\title{
HIV/AIDS Related Knowledge and Risk Behavior among Methadone Recipients in Liuzhou, China
}

KE King ${ }^{1,2}$, R Stephenson ${ }^{2}$, J Zhuo ${ }^{3 *}$ and J Hsia ${ }^{4}$

${ }^{1}$ Department of Epidemiology, School of Public Health, University of Michigan, Ann Arbor, MI, USA

${ }^{2}$ Hubert Department of Global Health, Rollins School of Public Health, Emory University, Atlanta, GA, USA

${ }^{3}$ Guangxi Zhuang Autonomous Region Centers for Disease Control and Prevention, Nanning, Guangxi Zhuang Autonomous Region, People's Republic of China

${ }^{4}$ Division of Reproductive Health, National Center for Chronic Disease Prevention and Health Promotion, Centers for Disease Control and Prevention, Atlanta, GA, USA

\begin{abstract}
China has a growing HIVIAIDS epidemic mostly among intravenous drug users. The purpose of this study was to examine the HIVIAIDS related knowledge and risk behaviors among a group of former intravenous drug users utilizing services at a methadone clinic in Guangxi Zhuang Autonomous Region. A sample of 140 methadone care recipients was surveyed on their demographic characteristics, drug-using behaviors, sexual behaviors, and factors related to risk behaviors including HIVIAIDS related awareness and knowledge. Although HIVIAIDS related knowledge was high, respondents reported that they did not use condoms, they shared needles, and they participated in commercial sex. Additionally, the respondents' perception of their risk for HIV infection was not always in accordance with their reported risk behaviors. This research suggests that methadone care recipients could act as a bridge population for HIV transmission to populations not involved with intravenous drug use. Further research on former intravenous drug users in China and their risk behaviors is warranted.
\end{abstract}

Keywords: HIV/AIDS; Intravenous drug users; Sexually transmitted infections; Methadone clinic; Guangxi zhuang autonomous region

\section{Introduction}

At the end of 2007, there were an estimated 33.2 million people living with HIV worldwide [1]. Throughout most of the world, HIV incidence peaked in the 1990's and now has begun to stabilize [2]. However, China is experiencing a growing HIV/AIDS epidemic with an increasing prevalence of HIV [2]. In 2003, the Chinese Ministry of Health reported that the number of HIV cases was increasing at an average rate of 30\% every year since 1999 [3,4]. In 2011, the prevalence of HIV infection in China was $0.06 \%$ (nearly 1 million people) and the HIV prevalence in China is expected to grow to 1.8 million people living with HIV/AIDS in 2015 [5,6]

In China HIV/AIDS is mostly reported among intravenous drug users (IDUs) [7,8]. In 2004, China officially reported 1.14 million drug users, but the estimated number is 3.5 million drug users and it is increasing each year [9]. In 1995, 35\% of drug users reported injecting drugs and this percentage increased to $49 \%$ in 2002 [9]. Among all reported HIV cases, $69 \%$ reported that they were infected with HIV through needle sharing [3]. Although the majority of HIV cases were reportedly transmitted through injection drug use, HIV transmission in China is increasingly found to be through sexual interaction [8]. An increase in sexually transmitted HIV infection was found between 1997 with $5.5 \%$ of HIV infections due to sexual transmission and 2002 with $10.9 \%$ of HIV infections due to sexual transmission [8].

Research has found that risky drug using behaviors are associated with risky sexual behaviors in the IDU population [10]. IDUs who share needles are more likely to have multiple sexual partners and low condom use than IDUs who do not share needles [10,11]. Drug users who are paid for sex are more likely to inject drugs and to share needles [11]. Moreover, it is found that HIV positive IDUs are more likely to share needles and have unprotected sex than HIV negative IDUs [10,12]. Due to the large population of IDUs in China, the high percentage of HIV infected IDUs, the increasing number of sexually transmitted HIV infections, and the link between risky drug behavior and risky sexual behavior, there is a growing concern of HIV transmission through sexual interactions between IDUs and non-IDUs $[9,10,13]$.

Although HIV is spreading quickly throughout China, knowledge of HIV/AIDS in China is low in the general population. A large study conducted in 2000, found that although the majority of people in China have heard of HIV/AIDS, many did not know the cause or that it could be detected and many did not know a single transmission route [14]. In a study of IDUs in China, it was found that only $11 \%$ of IDUs perceived they were at risk for HIV even though the majority of IDUs participated in high risk behavior such as sharing needles, using non-sterilized needles, participating in commercial sex, having multiple sex partners, and using condoms inconsistently $[15,16]$. Not only is knowledge on HIV/AIDS considerably low, but knowledge on safe sexual practice is also low especially in the young, sexually active, unmarried Chinese population [17]. These studies suggest a substantial gap in HIV/AIDS related knowledge and risk behavior.

HIV/AIDS prevalence rates are not uniform throughout China. Guangxi Zhuang Autonomous Region (GZAR), located in southern China, has among the highest rates of reported HIV infections in China. Sentinel data from 1998 reports that the HIV/AIDS prevalence among IDUs in GZAR is greater than 10\% [9]. Due to a high prevalence of HIV/AIDS and a large number of IDUs, GZAR is the ideal setting to study drug-using and sexual risk behavior among IDUs. This study examined the HIV/AIDS related knowledge and risk behavior among former IDUs in Liuzhou city, GZAR, China.

This study aims to add to the growing body of literature that

*Corresponding author: Jiatong Zhuo, MD, M.P.H., Centers for Disease Contro and Prevention, Guangxi Zhuang Autonomous Region, 18 Jinzhou Road, Nanning Guangxi, 530028 China, Tel: 086-771-251-8666; E-mail: Zjta28@163.com

Received February 10, 2012; Accepted April; 19, 2012; Published April 21, 2012

Citation: King KE, Stephenson R, Zhuo J, Hsia J (2012) HIVIAIDS Related Knowledge and Risk Behavior among Methadone Recipients in Liuzhou, China. J AIDS Clinic Res S1:007. doi:10.4172/2155-6113.S1-007

Copyright: ( 2012 King KE, et al. This is an open-access article distributed unde the terms of the Creative Commons Attribution License, which permits unrestricted use, distribution, and reproduction in any medium, provided the original author and source are credited. 
Citation: King KE, Stephenson R, Zhuo J, Hsia J (2012) HIVIAIDS Related Knowledge and Risk Behavior among Methadone Recipients in Liuzhou, China. J AIDS Clinic Res S1:007. doi:10.4172/2155-6113.S1-007

\begin{tabular}{|c|c|c|}
\hline Age & $n$ & $\%$ \\
\hline $21-34$ & 71 & 52.9 \\
\hline $35+-39$ & 63 & 41.1 \\
\hline \multicolumn{3}{|l|}{ Ethnicity } \\
\hline Han & 113 & 80.7 \\
\hline Minority & 27 & 19.3 \\
\hline \multicolumn{3}{|l|}{ Child } \\
\hline No & 79 & 57.7 \\
\hline Yes & 58 & 42.3 \\
\hline \multicolumn{3}{|l|}{ Married } \\
\hline No & 70 & 51.9 \\
\hline Yes & 65 & 48.1 \\
\hline \multicolumn{3}{|l|}{ Sex } \\
\hline Male & 111 & 79.9 \\
\hline Female & 28 & 20.4 \\
\hline \multicolumn{3}{|l|}{ Birthplace } \\
\hline Urban & 130 & 92.9 \\
\hline Rural & 10 & 7.1 \\
\hline \multicolumn{3}{|l|}{ Time in Liuzhou } \\
\hline Less than 1 year & 3 & 2.31 \\
\hline More than 1 year & 127 & 97.7 \\
\hline \multicolumn{3}{|l|}{ Currently Employed } \\
\hline Yes & 32 & 23.4 \\
\hline No & 105 & 76.6 \\
\hline \multicolumn{3}{|l|}{ Years of Education } \\
\hline $0-9$ Years & 68 & 59.7 \\
\hline 10-16 Years & 46 & 40.3 \\
\hline \multicolumn{3}{|l|}{ Profession } \\
\hline Professional & 23 & 26.7 \\
\hline Laborer & 12 & 13.9 \\
\hline Other & 51 & 59.6 \\
\hline \multicolumn{3}{|l|}{ Salary } \\
\hline No Salary & 33 & 55.9 \\
\hline 100 - 800 yuan/month & 18 & 30.5 \\
\hline $801-10000$ yuan/month & 8 & 13.7 \\
\hline
\end{tabular}

Table 1: Demographic Characteristics of Methadone Care Recipients at One Methadone Clinic in Liuzhou City in GZAR, China.

incidence of HIV in China may be increasing due to the IDU population engaging in risky sexual behavior with the non-IDU population. Specifically, this study will describe a population of methadone care recipients, identify HIV/AIDS related risk behaviors, awareness and knowledge and examine potential associations. Determining factors related to HIV transmission among former IDUs is crucial to better understanding the evolving transmission pathways in China.

\section{Materials and Methods}

This study employed a cross-sectional design to examine the HIV/ AIDS related knowledge and risk behaviors among methadone care recipients. Data were collected at a methadone clinic in Liuzhou city in GZAR, China in the summer of 2006. The study was conducted in cooperation with the GZAR Centers for Disease Control and Prevention (GZAR-CDC). Study participants were recruited through clinic staff referral. Respondents were included in the study if they were over 18 years old, were using services at the methadone clinic, and had self-reported participation in illicit drug injection in their lifetime. The majority of respondents reported beginning services at the methadone clinic within the previous year, with a small minority who began using services in the late 1990s. Using convenience sampling, 143 methadone care recipients were interviewed by clinic staff. This number includes all methadone care recipients who received services at the methadone

clinic where the data collection took place. Although no one refused to participate, three respondents refused to answer most of the forty questions and were excluded from the analysis. The final study sample included 140 methadone care recipients.

Emory University's Institutional Review Board (IRB) and the GZAR-CDC approved this study. Clinic staff members were instructed to orally consent each respondent and to ensure that each respondent was aware they had the right to withdraw from the study or refuse to answer any questions. All responses on the survey were confidential. All interviews were conducted in Mandarin by trained clinic staff. No identifying information was recorded on the questionnaires and all of the questionnaires were kept at the GZAR-CDC in China.

The questionnaire in this study was adapted from the Model "B" Standard Demographic Health Survey (DHS) 2004. Using information from the literature on IDUs in China, the questionnaire was modified to include more culturally relevant questions for the study population and a section on drug-using behavior. The additional questions were informed by literature, information gathered at the GZAR-CDC, and through a pilot study that was performed at the beginning of the study with participants at the methadone clinic. The HIV serostatus of the study participants was not asked; therefore status for all participants is unknown. The questionnaire was translated and back-translated to confirm the accuracy of the translation from English to Mandarin.

Data were entered in Microsoft Excel, 2000 [18] and analyzed in SAS 9.1.3 [19]. The data were cleaned and the variables that had missing data were cross-tabulated with demographic characteristics, which confirmed that there were no differences between data that

\begin{tabular}{|c|c|c|}
\hline Age at first drug use & $\mathbf{n}$ & $\%$ \\
\hline $10-19$ & 20 & 17.5 \\
\hline $20-29$ & 68 & 59.7 \\
\hline $30+$ & 26 & 22.8 \\
\hline \multicolumn{3}{|l|}{ Cleaned needle at last injection } \\
\hline No & 33 & 28.2 \\
\hline Yes & 84 & 71.8 \\
\hline \multicolumn{3}{|l|}{ Method to clean needle } \\
\hline With bleach, alcohol, boiling water & 45 & 44.1 \\
\hline With water that is not boiled or never cleaned & 57 & 55.9 \\
\hline \multicolumn{3}{|l|}{ Ever shared needles } \\
\hline No & 99 & 79.2 \\
\hline Yes & 26 & 20.8 \\
\hline \multicolumn{3}{|l|}{ Group that shared needles } \\
\hline Roommates & 3 & 9.7 \\
\hline Friends & 21 & 67.7 \\
\hline Family & 3 & 9.7 \\
\hline Other & 4 & 12.9 \\
\hline \multicolumn{3}{|l|}{ Inject with a group } \\
\hline No & 44 & 33.3 \\
\hline Yes & 88 & 66.7 \\
\hline \multicolumn{3}{|l|}{ Reason to first use drugs } \\
\hline Experimentation & 96 & 68.6 \\
\hline Peer Pressure & 20 & 14.3 \\
\hline Relaxation & 13 & 9.3 \\
\hline Other & 11 & 7.8 \\
\hline \multicolumn{3}{|l|}{ Reason to go to methadone clinic } \\
\hline Wanted to get off drugs & 128 & 91.4 \\
\hline Friends/Family Insisted & 12 & 8.6 \\
\hline
\end{tabular}

Table 2: Drug-Using Behaviors of Methadone Care Recipients at One Methadone Clinic in Liuzhou City in GZAR, China. 
Citation: King KE, Stephenson R, Zhuo J, Hsia J (2012) HIVIAIDS Related Knowledge and Risk Behavior among Methadone Recipients in Liuzhou, China. J AIDS Clinic Res S1:007. doi:10.4172/2155-6113.S1-007

\begin{tabular}{|l|c|c|}
\hline Age at first sex & $\mathbf{n}$ & $\%$ \\
\hline $14-19$ & 25 & 40.9 \\
\hline $20-29$ & 34 & 55.8 \\
\hline $30-32$ & 2 & 3.3 \\
\hline Condom at last sex & & \\
\hline No & 69 & 69.0 \\
\hline Yes & 31 & 31.0 \\
\hline Reason to use a condom & 19 & 27.5 \\
\hline Wanted to prevent STI/HIV & 17 & 24.6 \\
\hline Wanted to prevent pregnancy & 12 & 17.4 \\
\hline Prevent both STI/HIV and pregnancy & 1 & 1.5 \\
\hline Partner has other sexual partners & 5 & 7.3 \\
\hline Partner insisted & 15 & 21.7 \\
\hline Other & & \\
\hline Reason not to use a condom & 112 & 80.0 \\
\hline Not available - cost too much & 10 & 7.1 \\
\hline No perceived risk & 18 & 12.9 \\
\hline Condom is uncomfortable & & \\
\hline Number of sex partners in the last year & 11 & 17.4 \\
\hline None & 43 & 68.3 \\
\hline One & 9 & 14.3 \\
\hline More than one & & \\
\hline Partner uses drugs & 108 & 92.3 \\
\hline No & 9 & 7.7 \\
\hline Yes & & \\
\hline Ever participated in commercial sex & & 17.1 \\
\hline No & & \\
\hline Yes & & \\
\hline & & \\
\hline
\end{tabular}

Table 3: Sex Behaviors of Methadone Care Recipients at One Methadone Clinic in Liuzhou City in GZAR, China.

were missing or not missing between all demographic characteristics. The frequencies for each variable were calculated and the number and percentage of respondents who answered each question was reported. Odds ratios were then calculated to look at associations between three categories of dependent variables (drug using behavior, sexual behavior, HIV/AIDS related knowledge) and four outcome variables assessing the risk for HIV transmission. Three of the outcome variables (using a condom at last sex, participation in commercial sex and sharing needles) were selected according to the literature that identified these factors as important risk factors for HIV among IDUs and the fourth outcome variable (perceived risk of HIV) was chosen to document the proportion and factors associated with study participants reporting being at risk for HIV infection. The reported ages were grouped for analysis.

\section{Results}

Table 1 shows the demographic characteristics of the 140 methadone care recipients surveyed. The majority of respondents were male (79.9\%), Han (80.7\%), reported being between 30 and 39 years old, reported not having a child (57.7\%), and reported not being married (51.9\%). Table 2 shows the drug using behaviors of the 140 methadone care recipients surveyed. Most participants reported not ever sharing needles (79.2\%), but the majority of participants reported ever injecting drugs in groups (66.7\%). When asked if the participants cleaned their needle at last injection, $71.8 \%$ reported that they did clean their needle. However of those respondents who reported cleaning their needle at last injection, $41 \%$ did not clean their needle with bleach or boiling water. Table 3 shows the sex behaviors of the 140 methadone care recipients. Most study participants reported not using a condom the last time they had sex (69.0\%). The majority of participants surveyed reported that their most current sexual partner does not use drugs (92.3\%). Approximately $17 \%$ of study participants reported ever participating in commercial sex (ever paying for sex or being paid for sex). Of those who had participated in commercial sex, $14.3 \%$ were women ( $12 \%$ of all women surveyed) and $85.7 \%$ were men ( $18 \%$ of all men surveyed). Ninety-four percent of those who reported paying for sex were men, while $50 \%$ of those who reported having sex for money or drugs were men.

Most participants surveyed had heard of HIV/AIDS (97.8\%) (Table 4). The majority of participants knew that HIV is preventable (91.9\%), HIV is spread through unsafe sex $(97.8 \%)$, and that HIV is spread through unclean needles $(94.1 \%)$. Of the $97.8 \%$ who knew that HIV is spread through unsafe sex, $68.1 \%$ did not use condoms at last sex. Of the $94.1 \%$ who knew that HIV was spread through unclean needles, $19.5 \%$ reported ever sharing needles. Among the study participants, $67.2 \%$ knew a person who had HIV/AIDS, 54.8\% reported that they perceived themselves at risk for HIV, and $58.9 \%$ reported being tested for HIV/AIDS. The main reason for testing was an interest in their status (90.1\%) and the main reason for not being tested was the respondent reported no perceived risk for HIV (50\%).

Table 5 shows the associations between each of the four outcome

\begin{tabular}{|c|c|c|}
\hline Ever heard of AIDS & $\mathbf{n}$ & $\%$ \\
\hline No & 3 & 2.2 \\
\hline Yes & 135 & 97.8 \\
\hline \multicolumn{3}{|c|}{ Source of AIDS information } \\
\hline Radio & 52 & 37.4 \\
\hline TV & 94 & 67.6 \\
\hline Newspaper/Magazines & 69 & 49.6 \\
\hline \multicolumn{3}{|l|}{ AIDS is preventable } \\
\hline No & 11 & 8.1 \\
\hline Yes & 125 & 91.9 \\
\hline \multicolumn{3}{|c|}{ AIDS is spread through unsafe sex } \\
\hline No & 3 & 2.2 \\
\hline Yes & 133 & 97.8 \\
\hline \multicolumn{3}{|c|}{ AIDS is spread through unclean needles } \\
\hline No & 8 & 5.9 \\
\hline Yes & 128 & 94.1 \\
\hline \multicolumn{3}{|c|}{ Known anyone with HIVIAIDS } \\
\hline No & 39 & 32.8 \\
\hline Yes & 80 & 67.2 \\
\hline \multicolumn{3}{|l|}{ Tested for HIV } \\
\hline No & 53 & 41.1 \\
\hline Yes & 76 & 58.9 \\
\hline \multicolumn{3}{|c|}{ Reason to get tested for HIV } \\
\hline Interested in status & 70 & 90.9 \\
\hline Other & 7 & 9.1 \\
\hline \multicolumn{3}{|c|}{ Reason not to get tested for HIV } \\
\hline Fear of status & 15 & 30.0 \\
\hline Not interested in status & 9 & 18.0 \\
\hline Not at risk & 25 & 50.0 \\
\hline Other & 1 & 2.0 \\
\hline \multicolumn{3}{|c|}{ HIV can infect a healthy person } \\
\hline No & 14 & 11.3 \\
\hline Yes & 110 & 88.7 \\
\hline \multicolumn{3}{|l|}{ Perceived HIV risk } \\
\hline No & 52 & 45.2 \\
\hline Yes & 63 & 54.8 \\
\hline
\end{tabular}

Table 4: HIVIAIDS Awareness and Knowledge of Methadone Care Recipients at One Methadone Clinic in Liuzhou City in GZAR, China. 
Citation: King KE, Stephenson R, Zhuo J, Hsia J (2012) HIVIAIDS Related Knowledge and Risk Behavior among Methadone Recipients in Liuzhou, China. J AIDS Clinic Res S1:007. doi:10.4172/2155-6113.S1-007

Page 4 of 6

\begin{tabular}{|l|c|c|c|c|}
\hline $\begin{array}{l}\text { HIV/AIDS related Risk Behaviors, Awareness and } \\
\text { Knowledge }\end{array}$ & \multicolumn{4}{|c|}{ OUTCOMES } \\
\cline { 2 - 5 } & Condom at last sex & Participated in Commercial Sex & Ever Shared Needles & Perceived HIV risk \\
\hline Used drugs for more than 10 years & $0.90(0.35,2.32)$ & $2.10(0.61,7.16)$ & $0.12(0.02,0.56)$ & $2.00(0.85,4.68)$ \\
\hline Ever shared a needle & $0.70(0.24,2.06)$ & $4.15(1.42,12.15)$ & N/A & $6.53(1.78,23.99)$ \\
\hline Cleaned needle & $3.73(1.35,10.30)$ & $0.09(0.01,0.74)$ & $6.85(1.48,31.71)$ & $0.82(0.33,1.99)$ \\
\hline Respondent was over 24 years old at first injection & $0.73(0.29,1.79)$ & $0.25(0.07,0.87)$ & $5.37(1.65,17.47)$ & $0.66(0.29,1.51)$ \\
\hline Respondent's sexual partner uses drugs & - & $12.08(2.55,57.12)$ & $0.37(0.08,1.71)$ & $0.62(0.15,2.49)$ \\
\hline Respondent had one or more sex partner(s) in the past 12 months & $\mathrm{N} / \mathrm{A}$ & $1.95(0.21,17.44)$ & $4.80(1.02,22.37)$ & $0.48(0.11,2.07)$ \\
\hline Used a condom at last sex & $\mathrm{N} / \mathrm{A}$ & $1.39(0.48,3.99)$ & $0.70(0.24,2.06)$ & $1.69(0.65,4.36)$ \\
\hline Respondent was over 19 years old at first sex & $1.14(0.37,3.45)$ & $0.30(0.07,1.18)$ & $6.92(1.60,29.80)$ & $0.60(0.19,1.85)$ \\
\hline Perceived HIV risk & $0.58(0.22,1.51)$ & $1.56(0.56,4.34)$ & $6.53(1.78,23.99)$ & N/A \\
\hline Known someone with HIV/AIDS & $1.34(0.48,3.71)$ & $2.70(0.72,10.09)$ & $0.25(0.07,0.94)$ & $2.92(1.23,6.94)$ \\
\hline Respondent was tested for HIV/AIDS & $2.11(0.83,5.34)$ & $0.76(0.28,2.04)$ & $0.46(0.16,1.29)$ & $3.19(1.46,6.96)$ \\
\hline HIV is spread through sex & -- & $0.09(0.01,1.05)$ & $0.48(0.04,5.57)$ & -- \\
\hline HIV is spread through unclean needles & $0.92(0.15,5.31)$ & $1.00(0.11,9.05)$ & $0.40(0.08,1.81)$ & $0.80(0.12,4.99)$ \\
\hline
\end{tabular}

-- symbolizes that the sample was not large enough to analyze

N/A symbolizes that the analysis could not be done because the independent variable and dependent variable are the same

Table 5: Unadjusted Odds Ratios of Four Outcome Variables and HIVIAIDS related risk behaviors, awareness, and knowledge.

variables (condom at last sex, participation in commercial sex, sharing needles, and perceived risk for HIV) and HIV/AIDS related risk behaviors, awareness and knowledge. Respondents who reported that they ever shared a needle had a significantly higher odds of reporting that they were unemployed $(\mathrm{OR}=0.22(0.05,0.98))$, ever participated in commercial sex $(\mathrm{OR}=4.15(1.42,12.15))$, having one or more sexual partners in the past year $(\mathrm{OR}=4.80(1.02,22.37))$, having cleaned their needle at last injection $(\mathrm{OR}=6.85(1.48,31.71))$ and a significantly higher odds of reporting that they perceived themselves at risk for HIV $(\mathrm{OR}=6.53(1.78,23.99))$ than respondents who did not report ever sharing needles. Respondents who reported that they used a condom at last sex were significantly more likely to have reported cleaning their needle with boiling water or bleach at last injection $(\mathrm{OR}=3.73(1.35$, 10.30)). Those who reported cleaning their needle at last injection with boiling water or bleach had a significantly lower odds of reporting that they ever participated in commercial sex $(\mathrm{OR}=0.09(0.01,0.74))$ than respondents who did not report cleaning their needle. Respondents who reported that their current sexual partner uses drugs $(\mathrm{OR}=12.08$ $(2.55,57.12))$ and those who reported not being married $(\mathrm{OR}=0.24$ $(0.07,0.77))$ had a significantly higher odds of reporting that they ever participated in commercial sex than respondents who reported that their sexual partner does not use drugs After including the major risk factors for HIV in the model (cleaning needle at last injection, participating in commercial sex, using a condom at last sex, perceiving a risk for HIV, and sharing needles), a perceived risk for HIV was associated with sharing needles $(\mathrm{OR}=0.11(0.01,0.99))$ and cleaning needles with boiling water or bleach at last injection was associated with using a condom $(\mathrm{OR}=5.84(1.67,20.45))$.

\section{Discussion}

This study provides a description of methadone care recipients in Liuzhou. Methadone care recipients were chosen as the study population because of documented past intravenous drug use and therefore a population likely to have been at higher risk for HIV. While the majority of participants in the study reported never sharing needles, most participants in the study reported using intravenous drugs in groups. Literature suggests that IDUs who inject drugs in groups have an increased risk of sharing needles [20]. Considering this, the risk for HIV transmission through needle sharing may be underestimated in this study [21]. Most study participants reported not using a condom at last sex. The majority of methadone care recipients reported that condoms were not available or that condoms were too expensive. Furthermore, participation in commercial sex, defined as ever paying for sex or being paid for sex, was reported by $17.1 \%$ of the methadone recipients in this study. Our results regarding the association between drug use and commercial sex work among females could be explained by another study that documented high numbers female IDUs who were also commercial sex workers [22]. Our study adds new information that male IDUs are participating in commercial sex. The respondents who reported ever sharing needles had higher odds of reporting they ever participated in commercial sex. This result has been found in another study looking at HIV transmission in China and might be because commercial sex workers often share needles with clients [11]. Commercial sex workers may be more likely to share needles because they do not have the resources to obtain clean needles or may not be able to negotiate clean needles with their clients. Respondents who reported that they cleaned their needle with boiling water or bleach and used a clean needle at last injection had higher odds of reporting that they used a condom at last sex and lower odds of reporting that they participated in commercial sex. This illustrates that the study participants may be protecting themselves from HIV by engaging in safe sex. However, respondents that reported cleaning their needle with boiling water or bleach and using a clean needle at last injection had higher odds of ever sharing needles. Perhaps this is because the respondents who cleaned their needles may believe that it is safe to share needles after cleaning. These findings clearly indicate that there may be a combined HIV risk through injection drug use and risky sexual behavior. Additionally, most participants in this study reported engaging in high risk behavior and the majority reported that their most current sexual partner did not use drugs. Our findings provide evidence for the possible risk of HIV transmission to non-IDUs, highlighting the potential for IDUs to act as a bridge population for HIV transmission from IDUs to non-IDUs.

The majority of respondents in the study reported having heard of HIV/AIDS. Most participants reported knowing someone who had HIV/AIDS and the majority of respondents had been tested for HIV/AIDS. Although the knowledge of HIV/AIDS was high, many respondents did not report a perception that they were at risk for HIV. The perception of not being at risk for HIV was the main reason study participants did not get tested for HIV/AIDS. This gap in knowledge and risk assessment, also reported in other studies, provides a potential explanation for the high risk behavior found in this study and illustrates 
Citation: King KE, Stephenson R, Zhuo J, Hsia J (2012) HIVIAIDS Related Knowledge and Risk Behavior among Methadone Recipients in Liuzhou, China. J AIDS Clinic Res S1:007. doi:10.4172/2155-6113.S1-007

a large obstacle for HIV prevention and the importance of continued HIV/AIDS education $[14,16]$.

There are a number of limitations to this study. This study focused on drug using behavior in the past year, sexual risk behaviors in the past year, and current knowledge. This information may lead to temporal ambiguity due to the cross-sectional study design. Questions on drug use and sex both referred to the last year; however, given that respondents are in a methadone clinic, it is possible that last drug use occurred sometime before the last sex act. However, this study did not seek to establish causality. It did seek to establish the knowledge and HIV risk behaviors of former IDUs and relevant associations, given the demonstrated potential for higher levels of HIV infection among this population. Since the methadone care recipients may have a different risk profile from current intravenous drug users, generalizing to both populations has limitations. However, no study has defined the risk profile of methadone care recipients as different from intravenous drug users, therefore the groups were considered comparable for the purposes of this study. An additional limitation is that this study is not generalizable to other methadone clinic care recipient populations in China, because the methadone recipients in the study may have different effect modifiers than groups of methadone recipients in other areas of China. The survey did not ask if sexual practices differed between regular partners, casual partners, and commercial sex partners. This distinction is of potential importance when assessing risk and developing interventions. This study did not ask about information regarding men who have sex with men and therefore missed information regarding this possible risk behavior. This study also did not ask why some respondents reported that they ever shared needles, which would have been important for potential interventions.

Another limitation of this study was the small sample size. The sample size in this study was small because the lack of incentives to give study participants who complete the surveys and the lack of incentives for methadone clinics to participate. Additionally, some missing data on individual questionnaires exacerbated the problem of a small data set. Study respondents did not always answer every survey question, especially the questions that could be considered sensitive such as the number of sexual partners in the past year, condom at last sex, and age at first sex. However, none of the missing data were associated with the demographic characteristics of the study respondents. Therefore, the missing data is considered random. Subjects may have answered questions in a socially desirable manner as clinic staff administered the surveys and therefore this study may have underestimated risk behaviors. Despite these limitations, this study provides a unique view of the sexual behaviors and HIV/AIDS related knowledge among a high risk group in China and points to key areas of intervention to reduce the transmission of HIV both within the IDU population and to the non-IDU population.

This study has provided evidence that there is a clear disconnect between HIV/AIDS related knowledge and the individual decisions necessary to reduce risk behavior. Although the study participants reported knowledge that HIV is transmitted through unsafe sex and non-sterilized needles, study participants also reported engaging in unprotected sex and sharing needles when injecting drugs. From this study it is also clear that there is a possibility of HIV sexual transmission from the IDU population to the non-IDU population since many methadone care recipients reported participating in high risk behavior and because their most current sexual partner did not use drugs. Studies need to be completed that assess the HIV/AIDS related knowledge among the sexual partners of IDUs and to further examine the sexual risk behaviors between IDUs and their sexual partners. Public health interventions should continue to promote condom use, prevent needle sharing, promote proper needle cleaning, and discourage participation in commercial sex. Innovative research and targeted programs are urgently needed to intervene in China's expanding HIV/AIDS epidemic.

\section{Acknowledgements}

The Hubert Family Foundation financially supported this research. We would like to acknowledge the Liuzhou City Centers for Disease Control and Prevention and the following people for their contributions to this research Mingqiang $\mathrm{Li}$, Zhigan Gao, Jianpin Wang, and Jing Zhang. Lastly, we would especially like to thank the participants of our study.

\section{Disclaimer needed}

The findings and conclusions in this paper are those of the authors and do not necessarily represent the views of their supporting organizations, including the Centers for Disease Control and Prevention.

\section{References}

1. UNAIDS (2007) 2007 UNAIDS Annual Report: Knowing your epidemic. Joint United Nations Programme on HIVIAIDS (UNAIDS).

2. UNAIDS (2006) Report on the Global AIDS Epidemic, Joint United Nations Programme on HIVIAIDS (UNAIDS).

3. Chen HT, Liao Q (2005) A Pilot Study of the NGO-Based Relational Intervention Model for HIV Prevention Among Drug Users in China. AIDS Educ Prev 17 503-514.

4. Jie S (2004) The Chinese HIVIAIDS Epidemic and Current Response, in AIDS in Asia, Y. Lu, M. Essex, and E. Stiefvater (Editors). Kluwer Academic/Plenum Publishers, New York.

5. Zhang L, Gray RT, Wilson DP (2011) Modelling the epidemiological impact of scaling up HIV testing and antiretroviral treatment in China. Sexual Health.

6. Political commitment for HIVIAIDS control in China. (2011) Lancet 378: 1896.

7. Zhang KL, Ma SJ (2002) Epidemiology of HIV in China: Intravenous drug users, sex workers, and large mobile populations are high risk groups. BMJ 324: 803804

8. Yang H, Ding JP, Du Y (2004) Prevention of Sexual STI/HIV Transmission in Jiangsu Province, China, in AIDS in Asia, Y. Lu, M. Essex, and E. Stiefvater, Editors. 2004, Kluwer Academic/Plenum Publisthers: New York.

9. Qian HZ, Schumacher JE, Chen HT, Ruan YH (2006) Injection Drug Use and HIVIAIDS in China: Review of current situation prevention and policy implications. Harm Reduct J 3: 4.

10. Li X, Stanton B, Zhou Y (2000) Injection Drug Use and Unprotected Sex among Institutionalized Drug Users in China. Journal of Drug Issues 30: 663.

11. Yang H, Li X, Stanton B, Liu H, Liu H, et al. (2005) Heterosexual Transmission of HIV in China: A Systematic Review of Behavioral Studies in the Past Two Decades. Sex Transm Dis 32: 270-280.

12. Battjes RJ, Pickens RW, Amsel Z (1989) Introduction of HIV infection among intravenous drug abusers in low prevalence area. J Acquir Immune Defic Syndr 2: $533-539$.

13. Liu H, Grusky O, Li X, Ma E. (2006) Drug Users: A Potentially Important Bridge Population in the Transmission of Sexually Transmitted Diseases, Including AIDS in China. Sex Transm Dis 33: 111-117.

14. Holtzman D (2003) Current HIVIAIDS-related knowledge, attitudes, and practices among the general population in China: Implications for action. AIDS Science 3.

15. Wu Z, Qi G, Zeng Y, Detels R (1999) Knowledge of HIVIAIDS among health care workers in China. AIDS Education and Prevention 11: 353-363.

16. Lau JT, Feng T, Lin X, Wang Q, Tsui HY (2005) Needle sharing and sex-related risk behaviours among drug users in Shenzhen, a city in Guangdong, southern China. AIDS Care 17: 166-181.

17. Bai Y (2003) 100\% Condom Use Program in China Presentation available online at http://www.chain.net.cn/PDF/P7.pdf. National Center for AIDS Prevention and Control, Beijing, China. 
Citation: King KE, Stephenson R, Zhuo J, Hsia J (2012) HIVIAIDS Related Knowledge and Risk Behavior among Methadone Recipients in Liuzhou, China. J AIDS Clinic Res S1:007. doi:10.4172/2155-6113.S1-007

18. Microsoft, Microsoft Excel 2000, in Microsoft Office 2000, Microsoft, Editor. 2000.

19. SAS Institute, SAS 9.1.3, in SAS. 2007: Cary, North Carolina.

20. van Ameijden EJ, Coutinho RA (1998) Maximum impact of HIV prevention measures targeted at injecting drug users. AIDS 12: 625-633.
21. Liu W, Chen J, Rodolph M, Beauchamp G, Masse B, et al. (2006) HIV prevalence among injection drug users in rural Guangxi China. Addiction 101 1493-1498.

22. Lau JT, Zhang J, Zhang L, Wang N, Cheng F, et al. (2007) Comparing Prevalence of Condom Use Among 15,379 Female Sex Workers Injecting or Not Injectig Drugs in China. Sex Transm Dis 34: 908-916.

This article was originally published in a special issue, Risk behaviors: HIV/ AIDS handled by Editor(s). Dr. Karl Peltzer, Human Science Research Institute, South Africa. 